\title{
SINTESIS DAN KARAKTERISASI POLIMER SUPERABSORBAN DARI AKRILAMIDA
}

\author{
A. Zainal Abidin*, G. Susanto, N.M.T. Sastra, T. Puspasari \\ Kelompok Keahlian Perancangan dan Pengembangan Produk Teknik Kimia \\ Program Studi Teknik Kimia, Fakultas Teknologi Industri \\ Institut Teknologi Bandung \\ Jalan Ganesa 10, Bandung 40132 \\ Email: zainal@che.itb.ac.id
}

\begin{abstract}
Abstrak
Superabsorbent Polymer (SAP) merupakan polimer yang dapat menyerap air dalam jumlah yang sangat banyak. Dalam penelitian ini, polimer tersebut disintesis dari monomer akrilamida menggunakan crosslinker $\mathrm{N}, \mathrm{N}$-metilene bisakrilamide (MBA) dan inisiator amonium persulfat (APS). Pengaruh crosslinker dan inisiator terhadap karakteristik SAP dipelajari dengan melakukan variasi komposisi APS dan (MBA) masing-masing sebesar 0,1 \%-b, 0,2 \%-b, 0,6 \%-b, dan $1 \%$-b. Karakteristik produk SAP dipelajari dengan FTIR untuk menganalisis gugus fungsi yang terbentuk untuk menunjukkan bahwa polimerisasi betul terjadi dan produknya berupa SAP. Pengukuran kemampuan absorpsi SAP terhadap air destilasi menunjukkan bahwa kapasitas absorpsi terbesar yang dihasilkan oleh superabsorbent polymer dari penelitian ini sebesar14,5 gram air dalam 1 gram produk SAP yang dibuat. Kapasitas terbesar ini dimiliki oleh SAP dengan 0,2 \%-b APS dan 0,6 \%-b MBA. Studi lebih lanjut dengan SEM menunjukkan bahwa SAP yang memiliki kapasitas absorpsi tertinggi itu mempunyai morfologi permukaan yang berombak dan jumlah pori yang terbanyak sehingga luas permukaan kontak antara SAP dan air juga tertinggi.
\end{abstract}

Kata kunci: akrilamida, kapasitas absorpsi, superabsorbent polymer

\begin{abstract}
Superabsorbent polymer (SAP) is a material that can absorb water in a large amount in a short time. In this research, the polymer has been synthesized from acrylamide monomer (Am) using $\mathrm{N}, \mathrm{N}$ methylene bisacrylamide (MBA)as a cross-linker and ammonium persulphate (APS) as an initiator. Effects of MBA and APS on the SAP characteristic were studied by varying composition of MBA and APS each of $0.1 \%$-wt, $0.2 \%$-wt, $0.6 \%$-wt and $1.0 \%$-wt. SAP was characterized by measuring its absorption capacity to distilled water. Based on the experiment, the highest absorption capacity for 1 gram SAP is 14.5 gram water. The highest absorption is produced by SAP with APS $0.2 \%$-wt and MBA $0.6 \%$-wt. Further studies by using SEM showed that SAP which had high absorption capacity contained a lot of pores with the waving surface. Therefore, the surface contact area between SAP and water is high.
\end{abstract}

Keywords: acrylamide, absorption capacity, superabsorbent polymer

*korespondensi 


\section{Pendahuluan}

Superabsorbent polymer (SAP) adalah bahan hidrogel yang mampu menyerap air dalam jumlah yang sangat banyak dalam waktu yang singkat dan menjaga air terikat di dalamnya. Kemampuan hidrogel dalam menyerap air (swelling) dipengaruhi adanya gugus-gugus fungsi bebas dalam jaringan struktur molekulnya yang dapat mengikat air. Beberapa jenis gugus fungsi yang berpengaruh pada sifat swelling adalah gugus $-\mathrm{OH}$, -NH2, - $\mathrm{COOH}$, -CONH dan $-\mathrm{SO} 3 \mathrm{H}$.

Kemampuan penyerapan air ditentukan dengan menghitung selisih massa SAP yang sudah menyerap air pada massa yang relatif konstan dengan massa polimer kering dibagi dengan massa polimer kering. Jika nilai selisih tersebut makin besar, maka polimer tersebut memiliki kemampuan penyerapan air yang semakin baik (Chang dan Yoo, 1999).

Superabsorbent polymer merupakan hydrogel, yaitu polimer yang mempunyai karakteristik hidrofilik (menyukai air) dan tidak larut dalam air. Sifat hidrofilik disebabkan kehadiran dari gugus fungsi yang bersifat water-solubilizing, seperti gugus CONH yang dimiliki akrilamida. Ketika SAP dimasukkan ke dalam air atau pelarut akan terjadi interaksi antara polimer dengan molekul air. Penggembungan pada polimer terjadi dari keseimbangan antara gaya dispersif yang terjadi pada rantai hidrasi dan gaya kohesif yang menyebabkan SAP lebih rapat sehingga mengurangi penetrasi air ke dalam jaringan. Gaya kohesif ini disebabkan oleh ikatan kovalen crosslinking (Elliott, 1997).

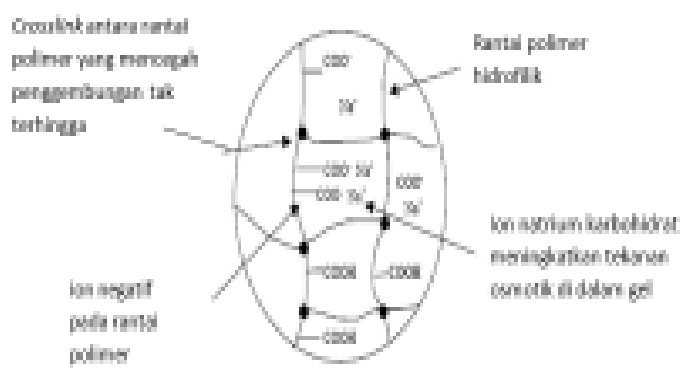

Gambar 1. Ikatan hidrofilik dan crosslink pada SAP (Elliott, 1997)

Gambar 1 menununjukkan bagian dari jaringan polimer. Rantai polimer pada SAP adalah hidrofilik, karena terdiri dari grup akrilamida -CONH. Ketika air masuk ke SAP terjadi interaksi antara polimer dan pelarut, yaitu hidrasi dan pembentukan ikatan hidrogen (Elliot, 1997). Mekanisme dari proses penggembungan yang berkontribusi pada kapasitas absorpsi akhir dari SAP dapat diilustrasikan sebagai berikut:

\section{a. Hidrasi}



Gambar 2. Interaksi antara COO- dan molekul air pada proses hidrasi SAP (Swantomo dkk., 2008)

Gambar 2 menampilkan interaksi dari grup akrilamida (-CONH) dengan molekul pelarut, dimana ion COO- berinteraksi dengan molekul air yang polar.

\section{b. Ikatan hidrogen}

Ikatan hidrogen (Gambar 3) merupakan interaksi yang kuat antara atom hidrogen dengan atom lain yang sangat elektronegatif yaitu atom F, O dan N. Ketiga atom ini memiliki keelektronegatifan paling tinggi diantara semua atom dengan nilai masing-masing secara berurutan yaitu 4, 3.5 dan 3. Ikatan yang terbentuk merupakan jenis ikatan antar molekul dengan energi ikatan sebesar 5-30 kJ/mol, yang jauh lebih besar daripada energi ikatan Van der Waals, namun lebih lemah daripada ikatan ionik maupun kovalen. Pada SAP, ikatan hidrogen akan terbentuk melalui interaksi antara atom hidrogen dari air dengan atom oksigen dari polimer. Hal inilah yang menjadi salah satu faktor yang membantu mekanisme penyerapan air pada SAP.

Mekanisme penggembungan pada SAP terjadi karena air akan terdifusi oleh tekanan osmotik SAP lalu berinteraksi dengan gugus hidrofilik. Setelah mencapai tahap kesetimbangan, air yang terserap akan terikat dengan gugus akrilamida membentuk ikatan hidrogen. Pada akhirnya air yang terserap ini akan tetap tertahan pada SAP sehingga polimer mengalami penggembungan.

Driving force untuk SAP menggembung adalah perbedaan antara 
tekanan osmotik di dalam dan di luar gel. Air dapat diserap oleh SAP karena tekanan osmotik air lebih rendah dari tekanan osmotik SAP. Sehingga, air akan masuk ke dalam SAP, karena zat akan berpindah dari tekanan osmotik yang rendah ke tekanan osmotik yang tinggi. Penetralan rantai polimer akan meningkatkan tekanan osmosis dari SAP dan meningkatkan kapasitas penggembungan. Tetapi kapasitas penggembungan ini dibatasi oleh derajat crosslink, maka hasil akhir dari kapasitas penggembungan adalah keseimbangan dari keduanya.

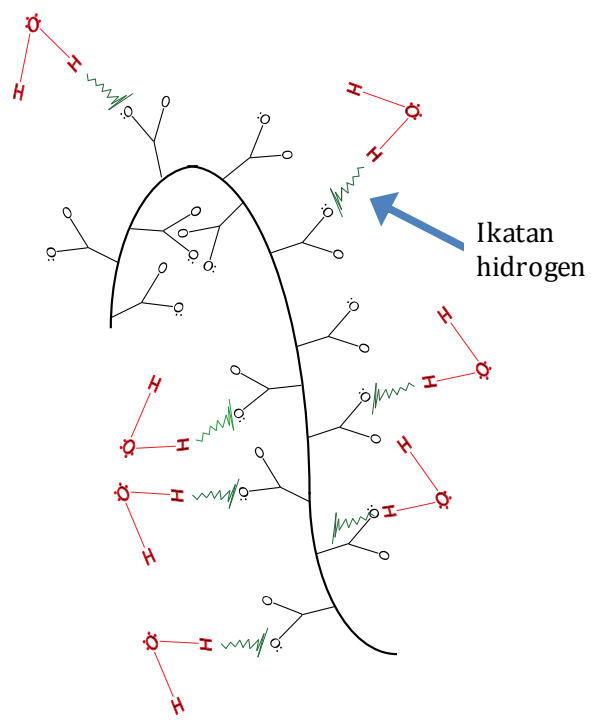

\section{Gambar 3. Pembentukan ikatan hidrogen}

Hal utama yang diangkat dalam penelitian ini adalah mempelajari cara sintesis SAP dari akrilamida serta karakterisasi keunikannya dalam menyerap air yang didukung oleh analisis kimia dan morfologi bahan tersebut. SAP disintesis dengan cara polimerisasi radikal dengan menambahkan amonium persulfat (APS) sebagai inisiator dan N,N-metiletilenbisakrilamide (MBA) sebagai crosslinker ke dalam reaktor agar bereaksi dengan monomer akrilamida (Abidin dkk., 2011a). Metode ini lebih sederhana dan lebih mudah dibanding metode lain, seperti teknik emulsi, yang pernah dilakukan oleh peneliti lain (Wan dkk., 2008). Beberapa peneliti juga menggunakan gelombang radiasi untuk proses inisiasi dan pembentukan crosslinking pada polimerisasi SAP (Swantomo dkk., 2008).

\section{Metodologi}

\subsection{Bahan dan Alat}

Bahan-bahan untuk pembuatan SAP ini diperoleh dari distributor bahan dan langsung dapat digunakan di dalam eksperimen. Adapun rincian bahan adalah akrilamida (Am), N,N-metilene-bisakrilamide (MBA) dan amonium persulfat (APS). Semuanya merupakan padatan murni dari Merck, Jerman.

Penelitian ini menggunakan peralatan laboratorium standar yang mencakup labu bundar berleher 4, oven, magnetic stirer, kondesor, pemanas listrik, pompa dan termometer.

\subsection{Sintesis SAP dari Akrilamida}

Dalam sintesis SAP dari akrilamida, 10 gram akrilamida mula-mula dimasukkan ke dalam pelarut $75 \mathrm{~mL}$ aqua $\mathrm{DM}$ di labu bundar. Campuran diaduk hingga homogen dengan memvariasikan jumlah MBA dan APS. Waktu reaksi berlangsung selama 3 jam dengan pemanasan perlahan-lahan hingga termperatur $70{ }^{\circ} \mathrm{C}$. Untuk membuat komposit, selulosa ditambahkan ke dalam labu bundar.

\subsection{Pengujian Kapasitas Absorbansi SAP}

Kapasitas penyerapan merupakan ukuran atau parameter yang digunakan untuk mengetahui seberapa banyak air yang dapat diserap oleh polimer. Besarnya nilai kapasitas penyerapan SAP dapat dinyatakan dalam bentuk persentase dengan Persamaan (1):

$\%$ kapasitas $=\frac{m_{t}-m_{o}}{m_{o}} \times 100 \%$

Keterangan :

$\mathrm{m}_{\mathrm{t}}$ : massa polimer setelah $\mathrm{t}$ waktu penyerapan [gram]

$\mathrm{m}_{\mathrm{o}}$ : massa awal polimer saat kering [gram]

Kenaikan persentase ini menandakan kemampuan penyerapan polimer yang makin besar.

\subsection{Karakterisasi SAP}

Karakterisasi SAP dilakukan dengan FTIR dan SEM (scanning electron micrograph). SEM bertujuan untuk mengetahui bentuk permukaan dan pori dari polimer yang akan mempengaruhi sifat absorpsi dari SAP. 


\section{Hasil dan Pembahasan}

\subsection{Spektroskopi FTIR SAP}

Produk polimer dari hasil percobaan ini dianalisis dengan FTIR untuk memastikan terjadinya polimerisasi, dengan melihat gugus-gugus fungsi yang muncul pada produk polimer tersebut. Hasil analisis FTIR di Gambar 4. Gambar ini menunjukkan bahwa SAP memiliki puncak-puncak yang merepresentasikan gugus fungsi seperti terangkum dalam Tabel 1.

\begin{tabular}{ll}
$\begin{array}{c}\text { Tabel 1. Puncak Grafik FTIR dan Gugus } \\
\text { Fungsi SAP (Silverstein dkk., 1981) }\end{array}$ \\
\hline \begin{tabular}{c} 
Puncak teramati \\
\multicolumn{1}{c}{$\mathbf{( c m}^{-1}$ ) }
\end{tabular} & $\begin{array}{c}\text { Gugus fungsi } \\
\text { terepresentasi }\end{array}$ \\
\hline 3632,3404, & - OH Stretching \\
3192 & $-\mathrm{NH}$ Stretching \\
2938 & $-\mathrm{CH}$ Stretching \\
1667,1571 & $-\mathrm{C}=\mathrm{O}$ Stretching \\
$1454,1408,1120$ & $-\mathrm{NH}$ Bending \\
1182 & $-\mathrm{NH}_{2}$ Bending \\
\hline
\end{tabular}

Gugus-gugus yang teramati dalam tabel di atas merupakan gugus yang biasa ada di dalam poliakrilamida yang bersifat hidrofilik (suka terhadap air). Gugus-gugus itu ada yang berasal dari monomer akrilamida, yaitu $-\mathrm{NH} 2,-\mathrm{CH}$ and $-\mathrm{C}=\mathrm{O}$, dan ada yang berasal dari crosslinker MBA, yaitu gugus -NH. Kehadiran gugus -NH dari crosslinker MBA menandakan bahwa ikatan silang pada polimer berhasil terbentuk. Grafik FTIR produk ini menunjukkan bahwa polimerisasi betul terjadi dan hasilnya berupa SAP.

\subsection{Kapasitas Absorpsi}

Kapasitas absorpsi SAP sebagai fungsi dari MBA dan APS diperlihatkan pada Gambar 5. Berdasarkan Gambar 5, kapasitas penyerapan tertinggi dimiliki oleh polimer yang menggunakan APS sebesar $0,2 \%$ dan MBA 0,6 \% dengan nilai 14,5 gram air/gram SAP. Walaupun tidak semuanya terlihat pada Gambar 5, profil kurva absorbansi secara umum dapat dijelaskan sebagai berikut.

Pada konsentrasi MBA rendah, kapasitas absorpsi SAP juga rendah. Hal ini disebabkan oleh rendahnya jumlah crosslink yang terbentuk di dalam SAP. Polimer yang tidak ter-crosslink akan larut dalam air sehingga tidak terhitung dalam angka kapasitas absorpsi. Ketika konsentrasi MBA naik, kapasitas absorpsi juga naik karena semakin banyaknya crosslink yang terbentuk sehingga polimer tidak ikut larut terbawa airdan kapasitas absorpsi naik. Tetapi bila konsentrasi MBA semakin tinggi, kapasitas absobpsi akan turun. Puncak tertinggi ini terjadi pada konsentrasi MBA yang bergantung pada konsentrasi APS di dalam polimer. Penurunan kapasitas absorbsi ini mungkin disebabkan oleh terlalu banyaknya

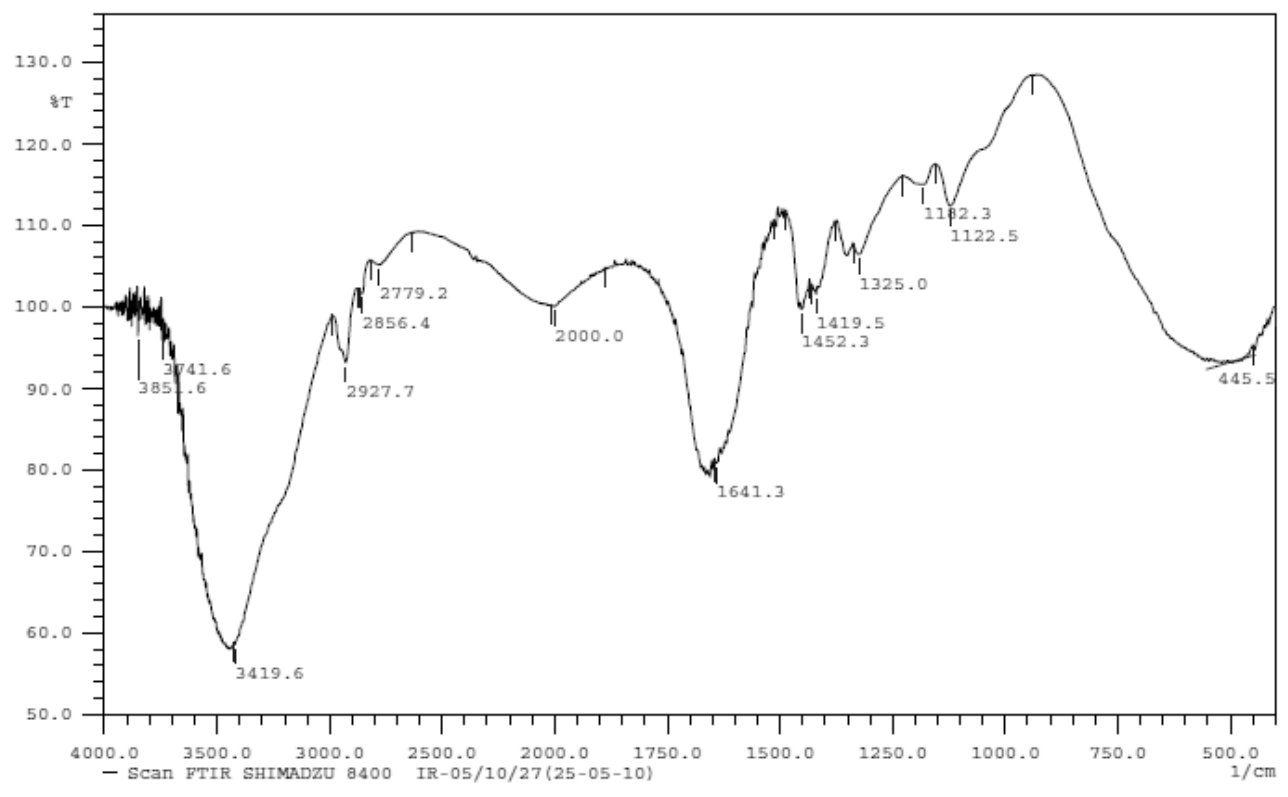

Gambar4.Hasil FTIR dari Superabsorbent Polymer $\left(4000-500 \mathrm{~cm}^{-1}\right)$ 


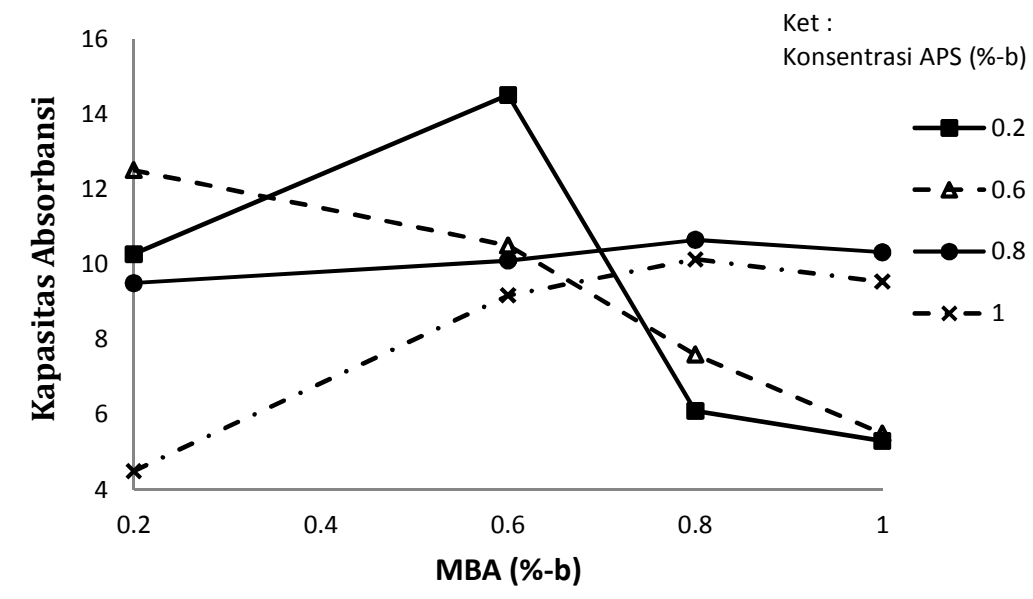

Gambar 5. Kapasitas absorbansi SAP pada variasi APS dan MBA

crosslink yang terbentuk di dalam SAP sehingga struktur polimer menjadi rapat, ukuran pori mengecil dan jumlahnya berkurang. Pengurangan pori ini akan menyebabkan pengurangan luas permukaan kontak SAP dengan air sehingga kapasitas absorpsi dari SAP makin kecil.

Hubungan antara kapasitas absoprsi atau derajat penggembungan $Q$ dengan struktur jaringan polimer $\mathrm{ve}_{\mathrm{e}} / \mathrm{Vo}$ (crosslink density) dapat dianalisis dengan menggunakan persamaan (2) (Flory, 1953).

$$
Q^{5 / 3}=\frac{\left(i / 2 v_{u} S^{0.5}\right)^{2}+\left(\frac{1}{2}-X\right) / V_{1}}{\left(\frac{v_{e}}{V_{o}}\right)}
$$

Keterangan :

Q : derajat penggembungan

$\mathrm{i} / \mathrm{v}_{\mathrm{u}} \quad$ : konsentrasi dari jaringan yang tidak menggembung

$S^{*} \quad$ : konsentrasi ionik larutan

$\mathrm{V}_{1} \quad$ : konsentrasi molar air

$\mathrm{ve}_{\mathrm{e}} / \mathrm{Vo}$ :densitas crosslink

Pada persamaan di atas, crosslink density ( $\mathrm{v}_{\mathrm{e}} / \mathrm{Vo}$ ) merupakan elemen penting yang mengendalikan kapasitas penggembungan SAP. Terlalu banyak crosslink yang terbentuk akan membuat terlalu sedikitnya area kosong pada polimer. Pengurangan area kosong tersebut akan menurunkan jumlah tempat pengikatan air di dalam jaringan polimer. Namun bila crosslinker yang digunakan terlalu kecil, maka akan membuat polimer terlepas satu sama lain dan larut dalam air.
Hubungan antara kapasitas absorbsi dengan kuantitas inisiator dapat dijelaskan dengan Persamaan 3 (Flory, 1953):

$v=\frac{\left[k_{p} / 2\left(f k_{d} k_{t}\right)^{1 / 2}\right][M]}{[I]^{1 / 2}}$

dengan:

$v \quad$ : panjang rantai kinetik

M : konsentrasi monomer

I : jumlah inisiator

$\mathrm{k}_{\mathrm{p}}, \mathrm{k}_{\mathrm{t}}, \mathrm{k}_{\mathrm{d}}$ : konstanta reaksi propagasi, terminasi dan disproporsionasi

f $\quad$ : faktor efisiensi

Dari Persamaan 3 terlihat bahwa peningkatan kuantitas inisiator $[I]$ akan mengakibatkan berat molekul polimer ratarata turun atau rantai polimer $(v)$ jadi pendek. Ini juga berarti akan menambah jumlah rantai polimer yang tidak membentuk jaringan polimer dan ikatan silang. Rantai polimer seperti ini tidak berkontribusi pada kapasitas absorpsi. Maka dari itu kapasitas absorpsi akan menurun dengan peningkatan jumlah inisiator. Akan tetapi bila jumlah inisiator terlalu sedikit, kapasitas absorpsi juga akan menurun. Hal ini dikarenakan berkurangnya jumlah radikal bebas yang dihasilkan oleh inisiator dan kecilnya jumlah radikal bebas ini menurunkan jumlah rantai polimer dan crosslink yang terbentuk.

Berdasarkan pengamatan langsung, SAP dari akrilamida ini memiliki kekenyalan yang relatif tinggi dan tidak mudah putus walaupun pada kondisi menyerap air yang maksimum. Hal ini mengindikasikan bahwa SAP poliakrilamida memiliki struktur yang kuat sebagai akibat dari adanya crosslink di dalamnya. 


\subsection{Karakterisasi Polimer dengan SEM}

Karakterisasi polimer dengan SEM bertujuan untuk melihat struktur fisik dari polimer. Hal penting yang perlu diamati adalah bentuk permukaan polimer serta jumlah dan besar mikropori yang ada di polimer. Mikropori ini merupakan tempat permeasi air dan tempat berinteraksi antara air dengan gugus hidrofilik dari SAP (Flory, 1953). Mikropori inilah yang banyak mempengaruhi kapasitas absorpsi dari SAP. Ada berbagai macam microphotograph dari hasil SEM yang memperlihatkan struktur fisik dari SAP antara lain struktur berombak, berpori, membentuk agregat, tidak beraturan dan sebagainya. Namun, berdasarkan penelitian sebelumnya (Gao dan Wang, 2008), struktur mikroporilah yang banyak berpengaruh terhadap kapasitas absorpsi polimer karena banyak meningkatkan luas permukaan kontak polimer dengan air. Luas permukaan kontak yang besar mengakibatkan tempat interaksi antara gugus hidrofilik $(-\mathrm{OH},-\mathrm{NH} 2,-\mathrm{COOH},-\mathrm{CONH})$ dengan air menjadi besar, dan tempat permeasi air meningkat.

Gambar 6 menunjukkan hasil SEM dari SAP dengan APS 0,6 \%-b dan MBA 1,0\%-b. Sampel ini memiliki permukaan yang lebih rata dan halus, mungkin tidak memiliki banyak mikropori sehingga kapasitas absorpsinya rendah yaitu 5,3 gram air/gram SAP.

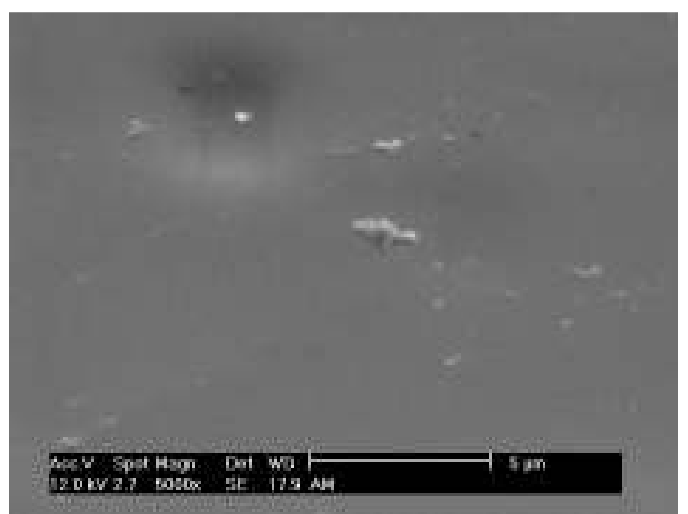

Gambar 6. Hasil SEM dari SAP dengan komposisi APS 0,6\% dan MBA 1,0\% pada pembesaran 5000x

Gambar 7 menunjukkan SAP dengan APS 0,2 \%-b dan MBA 0,6 \%-b, dengan struktur yang berombak dan mungkin memiliki lebih banyak mikropori yang membuat kemampuan absorbsinya lebih tinggi yaitu 14,5 gram air /gram SAP atau 3 kali lebih besar daripada sampel SAP sebelumnya. Di dalam SEM ini, mikropori itu digambarkan dengan titik hitam. Karena Gambar 7 tampak lebih hitam dari pada Gambar 6, maka besar kemungkinan SAP yang terakhir ini memiliki lebih banyak mikropori dibandingkan SAP yang sebelumnya. Hal ini didukung juga oleh Gao dan Wang (2008) yang menyatakan bahwa kapasitas absorpsi dipengaruhi oleh dua faktor yaitu bulk density dan porositas. Makin besar bulk density maka kapasitas absorpsi makin kecil. Makin besar porositas maka kapasitas absorpsi makin besar.

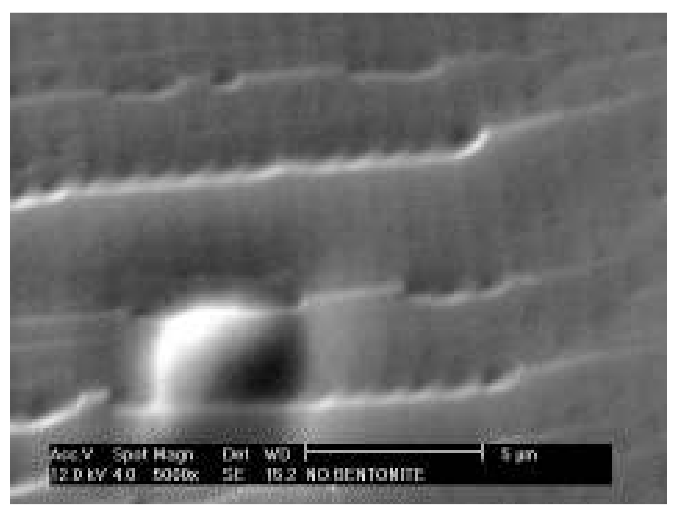

Gambar 7. Hasil SEM dari SAP dengan komposisi APS 0,2\% dan MBA 0,6\% pada pembesaran $5000 x$

Secara umum, hasil eksperimen menunjukkan bahwa material ini masih memiliki potensi untuk dinaikkan kapasitas absorpsinya dengan memperbesar luas kontak baik melalui permukaan bergelombang maupun jumlah dan ukuran pori. Hal ini dapat dilakukan baik secara perlakukan fisik maupun secara perlakuan kimia terhadap material ini. Topik ini akan menjadi pembahasan dalam penelitian berikutnya yang akan disajikan dalam tulisan setelah ini (Abidin dkk., 2011b).

\section{Kesimpulan}

Superabsorbent polymer dapat dibuat dari akrilamida dengan prinsip polimerisasi radikal melalui polimerisasi larutan. Analisis FTIR mengkonfirmasi hasil polimerisasi ini dengan memperlihatkan gugus-gugus hidrofilik yang biasa muncul pada spektra SAP poliakrilamida, termasuk pembentukan cross-linking oleh MBA. Kapasitas absorbsi SAP terbesar dari penelitian ini adalah 14,5 $\mathrm{g} / \mathrm{g}$ yang dimiliki oleh polimer dengan komposisi APS $0,2 \%$ dan MBA $0,6 \%$. 
Pengamatan morfologi dengan SEM terhadap SAP ini memperlihatkan bahwa struktur permukaan SAP ini berombak dan jumlah mikroporinya lebih besar dari SAP dari komposisi yang lain.Ini berarti bahwa kapasitas absorpsi SAP sangat dipengaruhi oleh struktur polimer dan jumlah pori yang terbentuk di dalamnya.

\section{Daftar Simbol}

$\mathrm{m}_{\mathrm{t}}$ : massa polimer setelah $\mathrm{t}$ waktu penyerapan [gram]

$\mathrm{m}_{\mathrm{o}}$ : massa awal polimer saat kering [gram]

$Q$ : derajat penggembungan

$\mathrm{i} / \mathrm{v}_{\mathrm{u}}$ : konsentrasi dari jaringan yang tidak menggembung

$S^{*}$ : $\quad$ konsentrasi ionic larutan

$\mathrm{V}_{1}$ : $\quad$ konsentrasi molar air

$v_{\mathrm{e}} / \mathrm{V}_{\mathrm{o}}$ : densitas crosslink

$v$ : panjang rantai kinetik

M• : $\quad$ kosentrasi awal monomer

I : $\quad$ kosentrasi awal inisiator

\section{Daftar Pustaka}

Abidin, A. Z.; Noezar, I.; Ridhawati., Synthesis and Characterizations of Superabsorbent Polymer Composite Based on Acrylic Acid, Acrylamide and Bentonite, Indonesian Journal of Material Science, 2011a, 12(2), 114-119.

Abidin, A. Z.; Sastra, N. M. T. P.; Susanto, G., Improving Absorption Capacity of Superabsorbent Polyacrylamide By Acrylic Acid Copolymerization, Proceeding International Conference on Innovation in Polymer Science and Technology, Bali, 28 November - 1 December 2011b.
Chang, S. C.; Yoo, J. S.; Woo, J. W.; Choi, J. S., Measurement and calculation of swelling equilibria for water/ poly (acrylamidesodiummallysufonate) systems, Korean Journals Chemical Engineering, 1999, 16(5), 581-584.

Elliott, M., Superabsorbent Polymers, BASF Report, 1997.

Flory, P. J., Principle of Polymer Chemistry, NY: Cornell University Press, Ithaca, New York, 1953; hal. 132-148, 576-594.

Gao, J.; Wang, A., Synthesis and characterization of superabsorbent composite by using glow discharge electrolysis plasma, Reactive and Functional Polymers, 2008, 68(9), 1377-1383.

Silverstein, R. M.; Bassler, G. C.; Morrill, T. C., Spectrometric Identification of Organic Compound, 7th edition, John Wiley and Sons: New York, 2005; hal. 248-283.

Swantomo, D.; Megasari, K.; Sataaji, R., Pembuatan Komposit Polimer Superabsorben dengan mesin Berkas Elektron, Prosiding Seminar Nasional IV SDM Teknologi Nuklir, Yogyakarta, 25-26 Agustus 2008.

Wan, T.; Wang, L.; Yao, J.; Ma, X.; Yin, Q.; Zang, T., Saline solution absorbency and structure study of poly (AA-AM) water superabsorbent by inverse microemulsion polymerization, Polymer Bulletin, 2008, 60(4), 431-440. 